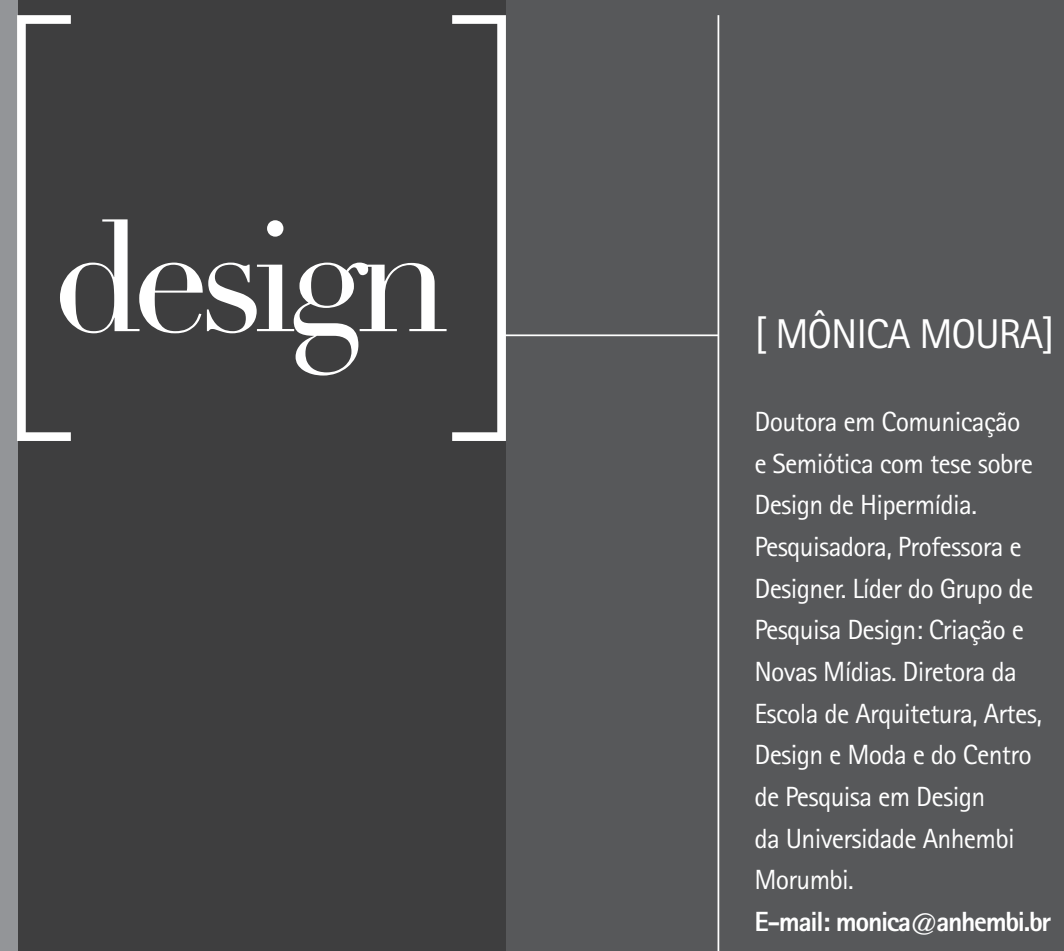




\section{Design Contemporâneo e suas Dobras (I)}

Falar do design contemporâneo é uma condição essencial, não apenas para registro histórico, mas especialmente para observarmos de maneira mais atenta a complexidade e a importância do design nos nossos dias. Este artigo é um começo de conversa, pois há muitas questões a serem tratadas a respeito, tanto no âmbito internacional quanto no plural universo brasileiro.

De onde vem a tal contemporaneidade do design? Há alguns caminhos, vamos tratar de um deles neste artigo, deixando para as próximas edições a continuidade deste pensar, observar e analisar o design contemporâneo.

A funcionalidade rígida e sem espaço ao lúdico, a limpeza da forma, a grade como uma estrutura de padrões determinados, os princípios "a forma segue a função" e "menos é mais" caíram por terra mediante as mudanças tecnológicas e de linguagem destes tempos pós-modernos.

As possibilidades de construção e desconstrução, apropriação e citação, articulação e modificação, velocidade, relação e acesso a imagens de todos os tempos e épocas possibilitadas pelos paradigmas do ciberespaço, cultura digital, mobilidade virtual e complexidade da sociedade da informação determinaram a ampliação da linguagem e dos elementos conceituais e projetuais do design.

Portanto, os princípios clássicos funcionais e formalistas que foram pensados para o universo bidimensional do design gráfico ou para o universo tridimensional do design de produto não bastam para atender as características do design contemporâneo em todas as suas vertentes.

As mudanças culturais, sociais e tecnológicas implicam modificações no campo do design no qual são gerados novos padrões de criação, de produção e de percepção. Nestes tempos, como este em que vivemos, o design é revalorizado e torna-se campo de essencial importância. Porém, é necessário tratar de sua complexidade e não apenas da forma exterior como a mídia e o marketing em geral vêm tratando.

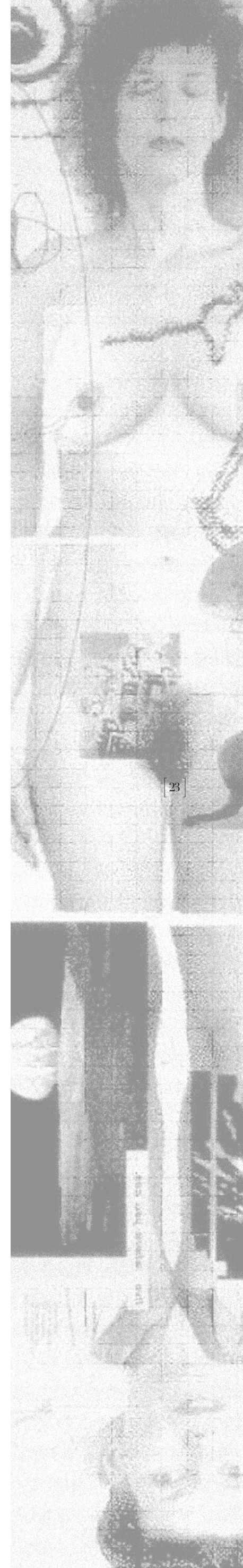


A experimentação dos novos meios e linguagens pode ser apontada desde o início dos anos de $1980^{[1]}$ quando na área de design começaram a proliferar projetos e peças repletos de imagens fragmentadas, em fusão, híbridas indicando uma nova estética e uma diferente maneira de criar e projetar. Designers americanos como April Greiman, Rudy VanderLans, Katherine McCoy, entre outros, começaram a utilizar e experimentar as ferramentas e as possibilidades do sistema e programas dos computadores que acabavam de chegar ao mercado.

Estes designers compreenderam rapidamente que o sistema informático e computacional trazia um novo paradigma e abria uma nova era de possibilidades para 0 design gráfico. Também perceberam que a tecnologia digital alterava o processo de criar e fazer design de modo significativo. A rapidez associada à facilidade de fazer e desfazer, a geração de uma série possibilidades gráficas somadas à finalização com qualidade profissional mostravam-se de forma muito positiva.

A designer April Greiman indicava que esta nova maneira de produzir levava a uma condição de incerteza e instabilidade que se estendia a todo o projeto. Nada era definitivo e físico tudo podia ser eliminado e modificado a todo instante, afinal no mundo digital nada está definitivamente acabado, qualquer arquivo de dados pode ser reconsiderado e reutilizado a qualquer momento o que permite ter sempre em vista um grande número de opções e variações. Até os acidentes, os ruídos e erros podem se tornar elementos da linguagem projetual e as limitações técnicas podem tornar-se partido do projeto, desde que trabalhadas conceitualmente.

Um dos exemplos destas transformações e da nova estética emergente foi o cartaz criado e desenvolvido por Greiman para a revista Design Quarterly, no 133, no ano de 1986. Este cartaz é uma declaração da associação da técnica, da linguagem digital, do hibridismo presentes nos projetos a partir de então. 0 cartaz de 0,60 X 1,80 cm apresenta um auto-retrato, uma imagem em tamanho natural de Greiman nua com todo o seu corpo revestido de textura obtida a partir de pontos e pequenas linhas que indicam a presença dos pixels como elemento mínimo da construção imagética computacional. Abaixo e entre o espaço de seus pés, a imagem de seu rosto com os cabelos presos e um olhar frontal direto ao observador representam o seu duplo espiritual, assim declarado pela própria designer, fato reforçado pela presença do título The spiritual dowble na lateral desta imagem. Além disto, há uma série de imagens sobrepostas e justapostas ao seu corpo: figuras geométricas, representações do universo, planetas, dinossauro, cérebro, astronauta, símbolos lunares, míticos e sexuais, mãos em diversos gestos e representações pré-históricas que convivem com uma linha do tempo.

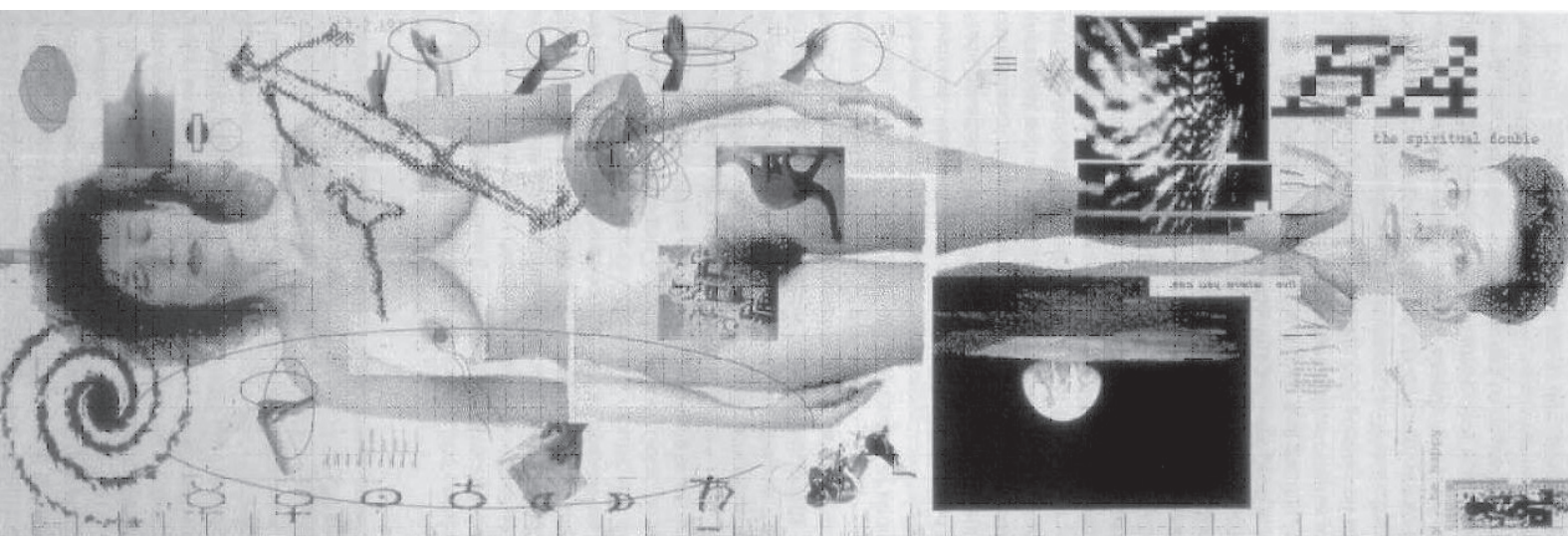

Na lateral da linha do tempo há uma seqüência de palavras que estabelecem uma margem indicando o limiar entre a representação e a realidade. Palavras de diversas naturezas: partículas físicas elementares (próton, nêutron, elétron), unidades de pesos e medidas (mili, micro, nano, quilo, pipa, tera), dicotomias (ordem, caos) indicam a pluralidade contemporânea e relações possiveis do universo computacional (jogue, 
faça sons). Ainda, palavras de ordem indicam a busca do prazer e do equilibrio espiritual: dance, sinta, não se preocupe, seja feliz!

Podemos observar a dicotomia ordem e caos que se apresenta a partir de contrastes preestabelecidos. A linha do tempo organizada e linear, tal como o paralelismo dos braços da imagem do corpo da designer que contrastam com os elementos inseridos num caos proposital. Um jogo de imagens que aludem ora à organização, ora à desorganização, localizadas em diversas áreas do cartaz.

0 conjunto da composição proporciona a criação de narrativas diversas a partir de uma série de acontecimentos reais e imaginários, ilustrados por meio de palavras e de imagens. Também nos leva a pensar que a designer apresenta as características da contraposição entre o universo material e imaterial, as questões da linearidade e não-linearidade, da imagem sintética e processada e da representação desenhada, do grafismo e da geometria, da forma orgânica e geométrica.

Este cartaz foi determinante por marcar a mudança da tecnologia e a introdução dos procedimentos informáticos no cotidiano do design gráfico, demonstrando uma série de novas possibilidades. 0 caráter excessivo presente no tamanho, na presença de vários detalhes gráficos, e a grande quantidade de informações o tornaram complexo. Esta peça instigou, atordoou o olhar e a visualidade das pessoas que tiveram contato direto com ela. É uma típica expressão da cultura digital contemporânea que exigiu (e continua exigindo) uma maneira diferenciada de olhar, perceber e se relacionar com a produção cultural e com o design pós-moderno.

April Greiman. Cartaz,

Design Quarterly,

n. 133, EUA, 1986.

\section{BIBLIOGRAFIA}

KOPP, Rudinei. Design Gráfico Cambiante. Santa Cruz do Sul: EDUNISC, 2002.

LUNENFELD, Peter. The Digital Dialectic. Boston: MIT Press, 2000.

MAEDA, John. Creative Code. Londres: Thames \& Hudson, 2004.

MANOVICH, Lev. The Language of New Media. Boston: MIT Press, 2000.

POINOR, Rick. No Mas Normas diseño gráfico posmoderno.

Barcelona: Editorial Gustavo Gili, 2003. 